\title{
A new synthetic face generation method for gender discrimination
}

\section{Ali Borji}

\begin{abstract}
Address: School of Cognitive Sciences, Institute for Studies in Theoretical Physics and Mathematics, Tehran, Iran
\end{abstract}
Email: Ali Borji - borji@ipm.ir

from Seventeenth Annual Computational Neuroscience Meeting: CNS*2008

Portland, OR, USA. 19-24 July 2008

Published: I I July 2008

BMC Neuroscience 2008, 9(SuppI I):P73 doi:I0.I I86/I47I-2202-9-SI-P73

This abstract is available from: http://www.biomedcentral.com/I47I-2202/9/SI/P73

(c) 2008 Borji; licensee BioMed Central Ltd.

A new parametric method for generating synthetic faces is proposed in this study which could be used for psychophysics studies on face perception [1]. Two separate programs, one in Delphi 2005 programming environment and another in MATLAB ${ }^{\circledast}$ is developed to sample real faces and generating synthetic faces respectively. The user can choose to utilize default configurations or to customize specific configurations to generate a set of synthetic faces. Head-shape and inner-hairline is sampled in a polar coor- dinate frame, located at the center of a line connecting two eyes at 16 and 9 eqi-angular positions. Three separate frames are placed at the left eye center, nose tip and lips to sample them with 20,30 and 44 angular points respectively. Eyebrows are sampled with 8 points in eye coordinate systems. Augmenting vectors representing these features and their distance from the origin generates a vector of size 95. For a synthesized face, intermediate points are generated using spline curves and the whole image is
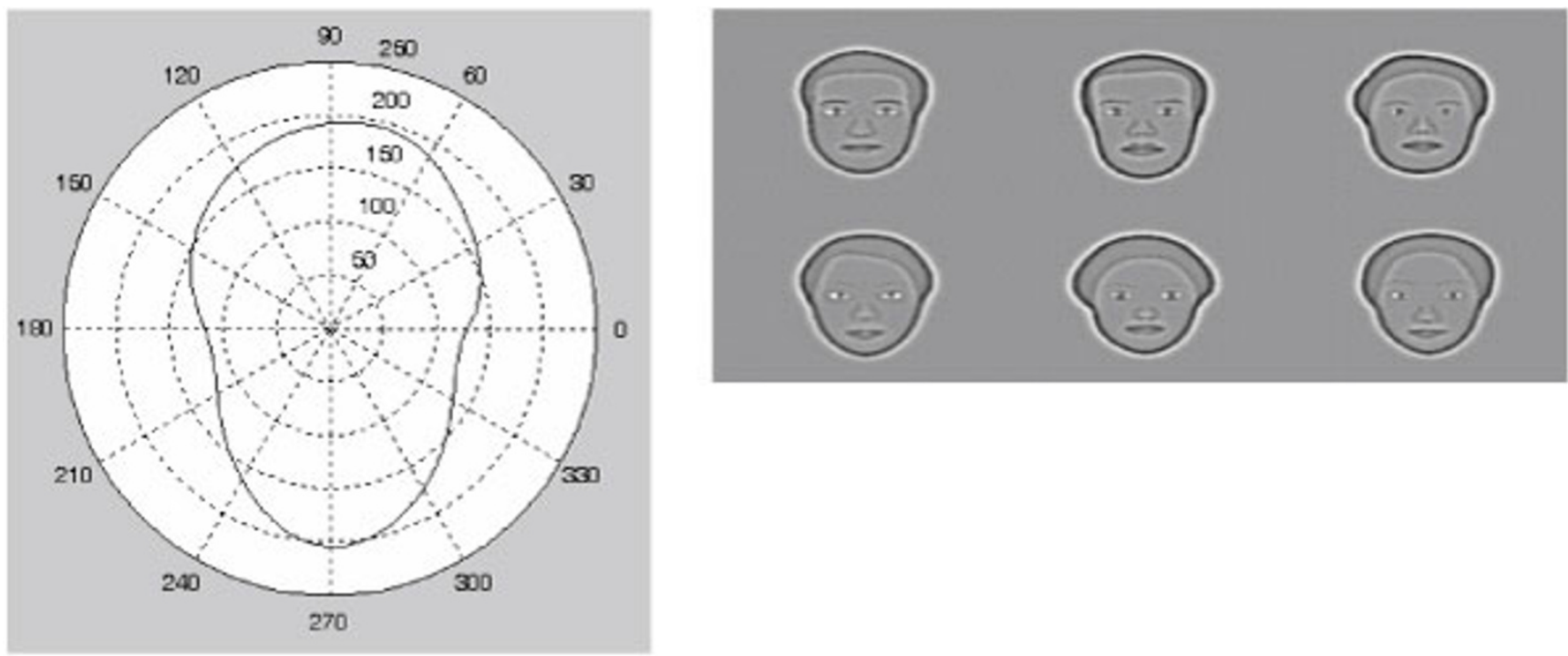

\section{Figure I}

Generating synthetic faces. Left, shows an interpolated synthetic face from sampled points. At right a number of final generated faces are shown after band pass filtering (Males are shown at top and females at bottom). It is also possible to interpolate two faces to each other and generate faces in between. 


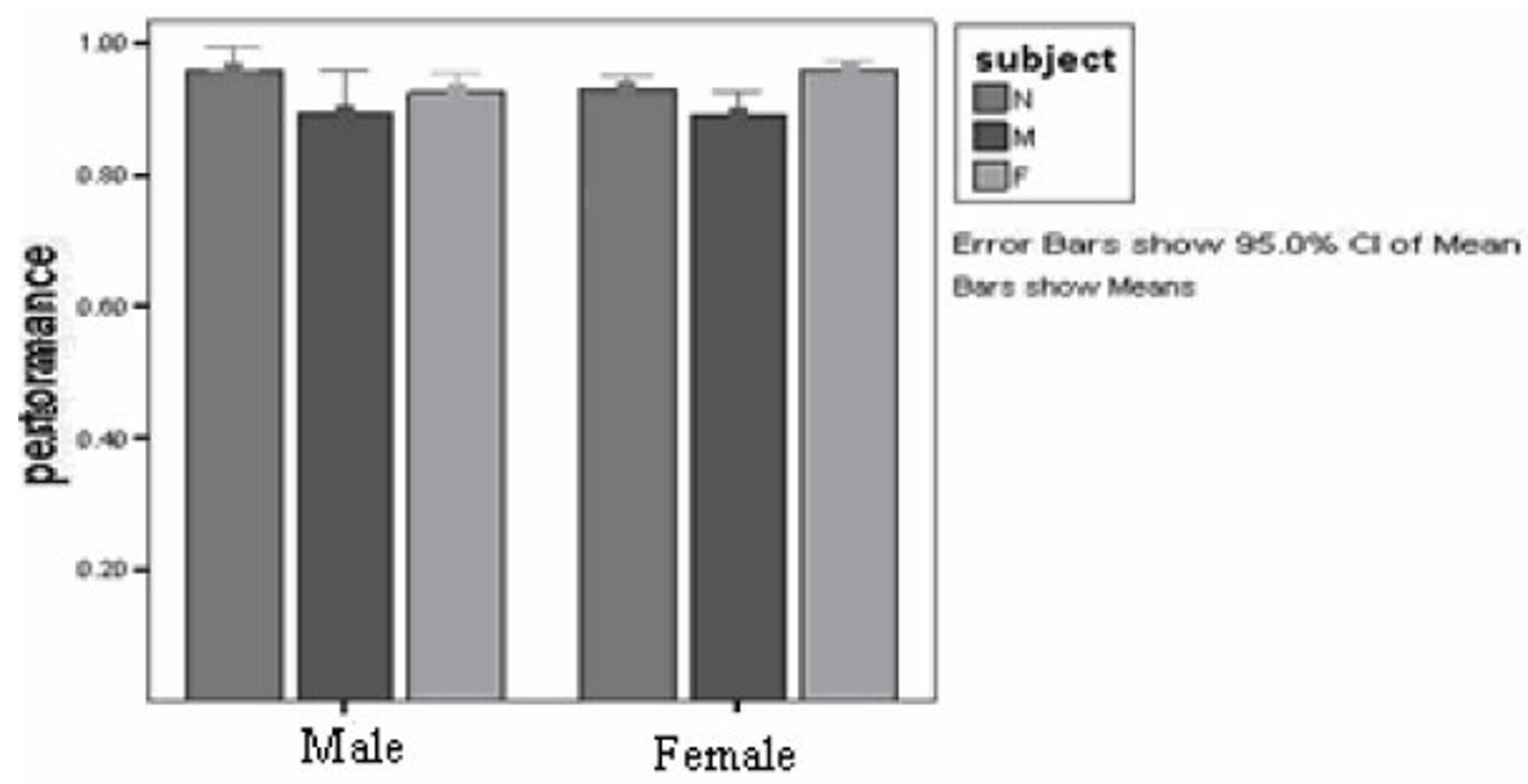

Figure 2

Performance in a discrimination task. We designed a gender discrimination task to see whether our faces carry information needed for gender categorization. In each trail, subjects were asked to determine the face gender by pressing a button indicating male or female gender. As shown in Fig. 2, mean subjects performance in this task was 0.92 and differences between female and male targets was not significant. The subjects had no significant difference as well $(P>0.05)$.

then band pass filtered [2]. Two experiments are designed to show that the set of generated synthetic faces matches very well with their equivalent real faces.

\section{Acknowledgements}

We thank H.R Wilson for his helpful comments and presenting us parts of his code.

\section{References}

I. Wilson HR, Loffler F, Wilkinson F: Synthetic faces, face cubes, and the geometry of face space. Vision Research 2002, 42:2909-2923.

2. Gold J, Bennett PJ, Sekuler AB: Identification of bandpass filtered letters and faces by human and ideal observers. Vision Research 1999, 39:3537-3560.
Publish with Bio Med Central and every scientist can read your work free of charge

"BioMed Central will be the most significant development for disseminating the results of biomedical research in our lifetime. "

Sir Paul Nurse, Cancer Research UK

Your research papers will be:

- available free of charge to the entire biomedical community

- peer reviewed and published immediately upon acceptance

- cited in PubMed and archived on PubMed Central

- yours - you keep the copyright
BiolMedcentral 